\title{
Using Geographical Information System for Mapping Public Schools Distribution in Jeddah City
}

\author{
Abdulkader A. Murad ${ }^{1}$, Abdulmuakhir I. Dalhat ${ }^{2}$, Ammar A Naji $^{3}$ \\ Faculty of Architecture and Planning \\ Department of Urban and Regional Planning \\ King Abdulaziz University, Jeddah, 80210, Saudi Arabia
}

\begin{abstract}
Geographical Information System (GIS) remains a unique tool use for school mapping for a clear understanding of the nature, planning, and distribution of educational facilities. The study carried out a GIS analysis for male primary and secondary schools' distribution in Jeddah city, Saudi Arabia, to show the significance of using GIS tools to assist the educational planning authorities. To understand, re-plan and address the location, distribution and availability challenges of the schools in Jeddah city. A Geodatabase for the study area was created, which incorporates education and population data collected from authorities. Spatial and network analyses are utilised to understand the location distribution, students' density, and the accessibility of the schools in the study region. The analyses results identified the services and students'; density, directional growth of the schools, drive-time service areas and served and un-served populace for the authorities in Saudi Arabia to make better planning decisions, address present and future challenges in the provision of primary schools to residents and most importantly to improve educational services. The findings revealed that shorter travel distances found in the denser (central) part of the city and some regions that need more schools.
\end{abstract}

Keywords-GIS; school mapping; educational facilities; geodatabase; spatial and network analysis

\section{INTRODUCTION}

Both urban and rural areas are witnessing considerable growth in all aspects, including the education sector. The change requires proper planning and distribution of educational facilities by Authorities to achieve equity and demand. Educational facilities planning is a unique method of planning schools' and facilities distribution, size, and spacing for best utilisation [1] at all levels to accelerate progress and prosperity in political, economic, social and cultural sectors [2]. It includes a broad range of planning and management related to the resources' allocation, location, and distribution of educational services [3]. Planning of schools involves mapping, the planning of schools' location to guarantee competent and impartial distribution, mainly when extensive reforms or considerable growth of educational system take place [4]. School mapping involves the creation of relational geospatial databases for demographic, educational, social and economic information for educational authorities to help decision-makers and planners [5]. It is an essential tool to understand the inequalities from the public authority's investment.
Consequently, public authority's investment determines the pattern of distribution of educational facilities. Also, school mapping is a strategic planning process that tries to address the deficiency in conscious effort to locate educational facilities in a place for maximum utilisation by a targeted population to their advantage [6]. It is, therefore, a dynamic vision of how the current and future education services look like to aid the implementation of policies and to help authorities to achieve better decision-making regarding location and distribution of schools across different geographical areas to ensure optimum utilisation. According to [7], school mapping is essential in promoting accessibility and equity in the distribution to avoid over-localisation or over-concentration of schools in certain areas while other areas are lacking. Another importance of school mapping is to create a conducive condition for achieving universal education [8]. Likewise, it is a means for research, gaging accessibility and aiding good decision-making in school for better policies [9].

\section{BACKGROUND}

The Kingdom of Saudi Arabia (KSA) is said to be the second-largest Arab state with an estimated total area of $2,250,000 \mathrm{Km}^{2}$ and a population of 34.2 million in 2019 , according to the General Authority for Statistics [10]. Positioned somewhere between 16' and 32' S and 35' and 55'N, Saudi Arabia bordering Iraq, Jordan and Kuwait in the North, Yemen in the South, the United Arab Emirates, o Oman, Qatar and the Arabian Gulf to the East and the Red Sea to the West [10]. Besides, the cities of KSA are centres of commerce and culture. Riyadh is the most prominent, central and administrative capital with an estimated population of 4.21 million. While, Jeddah is a commercial city, a gateway to Holy Makkah and Medina with an estimated population of 3.43 million. The third biggest city is the Holy Makkah city, with an estimated population of 1.32 million. The total gross enrollment ratio of school students, according to the Ministry of education report is $98.1 \%$, with an estimated total of 3.8 million students [11]. Table I compares the population of the three major cities kingdom, the area, students' enrollment and schools. Data obtained from the Ministry of Education shows that Riyadh city with the highest population, area, number of students and schools then Jeddah and Makkah cities followed respectively (Table I). 
TABLE I. DATA COMPARISON OF MAJOR CITIES IN KSA [11]

\begin{tabular}{|c|c|c|c|c|c|c|}
\hline \multirow{2}{*}{ City } & \multirow{2}{*}{$\begin{array}{l}\text { Population } \\
\text { (Million) }\end{array}$} & \multirow{2}{*}{$\begin{array}{l}\text { Area } \\
\left(\mathrm{Km}^{2}\right)\end{array}$} & \multicolumn{2}{|l|}{$\begin{array}{l}\text { Primary } \\
\text { Schools }\end{array}$} & \multicolumn{2}{|c|}{ Secondary Schools } \\
\hline & & & $\begin{array}{l}\text { No. of } \\
\text { Schools }\end{array}$ & $\begin{array}{l}\text { No. of } \\
\text { Students }\end{array}$ & $\begin{array}{l}\text { No. of } \\
\text { Schools }\end{array}$ & $\begin{array}{l}\text { No. of } \\
\text { Students }\end{array}$ \\
\hline Riyadh & 4.21 & 1,913 & 1,896 & 612,437 & 711 & 188,433 \\
\hline Jeddah & 3.43 & 1,765 & 1060 & 558,626 & 438 & 100,334 \\
\hline Makkah & 1.32 & 1,200 & 666 & 213,896 & 222 & 71,534 \\
\hline
\end{tabular}

In KSA, challenges particularly in students' enrolment and accessibility due to accelerated urban expansion, population growth, traffic congestion and lack of use of justifiable and suitable planning tool and scientific methods in the distribution planning of schools are currently the main issues in achieving equitable distribution and access to educational facilities in some parts of Jeddah city [12]. Equitable distribution means fairness in the distribution and planning of schools. Lagrab \& Aknin [3] stated that the mapping and distribution of the services could provide proper planning and considering a spatial multicriteria (based on geographic information system) which can assist in planning, management, and policymaking. In Educational facilities planning, GIS tools can offer innovative evaluation tools and complete information packages for evaluating facilities and service area distribution [12]. Therefore, the information can aid policymakers, for example, understanding the spatial distribution of existing educational facilities and their catchment areas, both the density schools and students, identifying and selecting schools' locations. GIS as a specialised computer program collects, stores, manipulates, retrieves and analyses spatial information that can assist in understanding the distribution of educational facilities [13]. It is a computer-based data framework fit for incorporating information from different sources to give the data needed for effective decision-making [14]. It has become a useful tool that offers critical understanding, depicts relationships and aids the visualisation of data in significant hotspots within a spatial environment [15]. Environmental Systems Research Institute (ESRI) stated that GIS technology exploits two kinds of data (spatial and attributes data). Spatial data is the information which defines the absolute and relative position of geographic features [16]. At the same time, attribute data known as tabular data describes the quantitative and qualitative characteristics of the spatial features.

According to Musa and Mohammed [17], several measures are available for evaluating spatial accessibility to educational facilities which include; imposing standards (i.e. travel time and catchment area distance) to schools. Point and kernel density, ring buffer and overlay analyses can be employed to present the distribution and accessibility of schools. Additionally, network analysis calculates the schools' proximity access and adequate travel time to various schools' locations within the neighbourhood or study area. However, similar studies carried out applied only spatial analyses like the case of Al-Enazi, Mesbah, \& Anwar [12] that applied overlay and buffer analysis in assessing the schools' spatial distribution in Jeddah city. The outcomes provided substantial evidence on the distribution of schools spatially with population density in different districts of Jeddah. Al-Rasheed \& El-Gamily [18] with a similar study in Kuwait presented the distribution of educational facilities by categorising parts of the city with no schools and failing to meet the least of students' needs using only spatial analysis.

Similarly, Aschale [19] presented a study on the assessment of schools' spatial distribution in Debre Markos town of NorthWestern Ethiopia using GIS to explain the spatial appropriation example of schools and the suitable future areas for the location of schools using various spatial analyses. Another study carried out in Kano, Nigeria by Olubadewo, Abdulkarim, $\&$ Ahmed [20] analysed the spatial distribution of primary schools using spatial analysis functions and concluded that most of the schools concentrate where the density of students is high, just like the case of Jeddah. Also, a study carried out by Lagrab and Aknin [3] on the suitability analysis for elementary schools in Mukalla districts of Yemen using spatial analyses; multiple ring buffer, then straight line distance measured, and map algebra of classified raster(s), applied to select suitable locations for the establishment of new schools.

The estimated driving time of students depends on age, mode of transportation, school choice policy, and a long drive to school may influence student's capacity to get to class on time [21]; thus, standard travel-time recommended by education authorities. A study carried out by Urban Institute reported that the average standard travel time to schools in most of the USA cities to be 10 minutes' drive [22]. In the case of Saudi Arabia, the spatial distribution of primary and secondary schools requires the use of the minimum and maximum criteria and standards of planning of schools approved standard catchment area for primary and secondary schools' location in Jeddah city is 500 and 2500 meters, respectively [23]. Moreover, similar previous studies carried out by wang et al. [24] and Sayed-Ahmad et al. [25] stated the international acceptable distance travel time standard to both primary and secondary schools as presented in Table II. The criteria are relative, not constant but depend on several planning variables. This study applies spatial analysis to classify schools, and network analysis to identify the travel time catchment area to schools in Jeddah city. The study also classifies the population that falls inside and outside the resulted travel time catchment area.

TABLE II. StANDARd CRITERIA FOR PlANNING SCHOOLS [23]

\begin{tabular}{|l|l|l|}
\hline Criterion & Primary Schools & Secondary Schools \\
\hline Catchment Area (Meters) & $500 \mathrm{~m}$ & $2500 \mathrm{~m}$ \\
\hline $\begin{array}{l}\text { Distance from residence to } \\
\text { school (Kilometers) }\end{array}$ & $0.5-1 \mathrm{~km}$ & $0.5-2.5 \mathrm{~km}$ \\
\hline $\begin{array}{l}\text { Distance from residence to } \\
\text { school (Minutes) }\end{array}$ & $10-15 \mathrm{mins}$. & $25-30 \mathrm{mins}$. \\
\hline $\begin{array}{l}\text { Number of } \\
\text { classrooms/School (Class) }\end{array}$ & $12-24$ classes & $18-30$ classes \\
\hline $\begin{array}{l}\text { Number of student/Class } \\
\text { (Students) }\end{array}$ & $20-30$ students & $20-30$ students \\
\hline $\begin{array}{l}\text { Area for each student/Area } \\
\text { (Square meters) }\end{array}$ & $15-25 \mathrm{~m}^{2}$ & $25-30 \mathrm{~m}^{2}$ \\
\hline
\end{tabular}




\section{MATERIAL AND METHODS}

\section{A. Study Area}

Jeddah city is the second biggest city in the KSA after the capital city, Riyadh. It is a commercial city with the largest Seaport, located in Makkah Province on the Arabian Red Sea. Murad [26] stated that the Jeddah urban boundary and the total area of $1765 \mathrm{~km}^{2}$ and $5460 \mathrm{~km} 2$, respectively. The city population estimated at around 3.43 Million in 2017. According to the UNESCO report, the total school enrollment percentage in Saudi Arabia by 2016 is $116.24 \%$, and the male enrollment percentage is $117.26 \%$ compared to $115.19 \%$ female [27]. Based on the report, the school enrollment exceeded $100 \%$ in Saudi Arabia because of the inclusion of over-aged and under-aged pupils on account of the early or late school admission and grade repetition.

The first Saudi educational system was set up in 1924, at first, with barely any western schools [28]. Moreover, the Education Ministry in 1953 was established, explicitly to improve the educational system for male students to meet international standards [29]. Ministry of Education represents the government in providing and supervising free general education for all residents that consist of the advancement of the national educational plan, issuing strategies, providing training programs and assessing the educational performance of teachers, students and schools at numerous stages [30]. With this, more schools constructed, and public education began to develop in the Kingdom and with an overall principle that the framework offers an equivalent prospect to all students notwithstanding their background. With regards to school management in KSA, the system is highly standardised, centralised and schools' leadership is gendered, where the boys' schools are managed by males and the females for girls' schools [31] due to the Islamic culture of Saudi Arabia.

Additionally, data obtained from the Ministry of Education was analysed using ArcGIS to show schools' categorisation and location of male public schools in Jeddah city (Fig. 1). All public schools are managed and funded by the government, while, the private schools are funded solely or partly by students' tuition and managed by the private body but regulated by the government [11]. Children attend primary schools for six years, a 3-year intermediate and a 3-year secondary cycle with a separate higher education program as stated by the Saudi Arabian Cultural Mission report in the USA [32]. Furthermore, public schools are separated into male and female schools in Saudi Arabia. In KSA, the Ministry of Education sets benchmarks, creates educational plans, and structures course books for all schools everywhere throughout the Kingdom. Consequently, all schools must actualise similar principles, educational plans, and course readings. The Kingdom authorities are improving to address apparent shortcomings in their international standing; it has allowed a multiplicity of schools (private and international) to increase, normally charging dues, while following the authorities educational program [33]. Accordingly, the authorities continue refining rules and benchmarks by offering quality training programs for teachers, improving guidelines for student assessment, expanding the utilisation of technology and education subsidy [28]. Similarly, King Abdullah bin AbdulAziz Project for Public Education Development established in 2007 [31] to transform the kingdom educational framework was to improve the education standard. The project initially set up 25 each of boys' and girls' secondary schools (Tatweer Schools) in 25 regions in Saudi Arabia, including Jeddah under Makkah province.

\section{B. The Database}

For this study, both analogue and digital data were collected, developed and updated into GIS format to form the database for this application (Fig. 2). Firstly, point data defining the schools-based locations converted to point features with the city district resolution in ArcGIS 10.2.1 by ESRI, Red- lands, CA, USA to present the location of schools in each district. Secondly, polygon and line data showing the city district boundaries/parcels and road network linked with point data and all the GIS converted attributes using ArcGIS application. Therefore, both the non-spatial and spatial data identified and characterised (Table III) which are linked together with detailed features of the study area (population, land use and school data) for different analysis. ArcGIS is then used to carry out various spatial and network analysis that presented the spatial spread of primary and secondary schools in the city Jeddah.

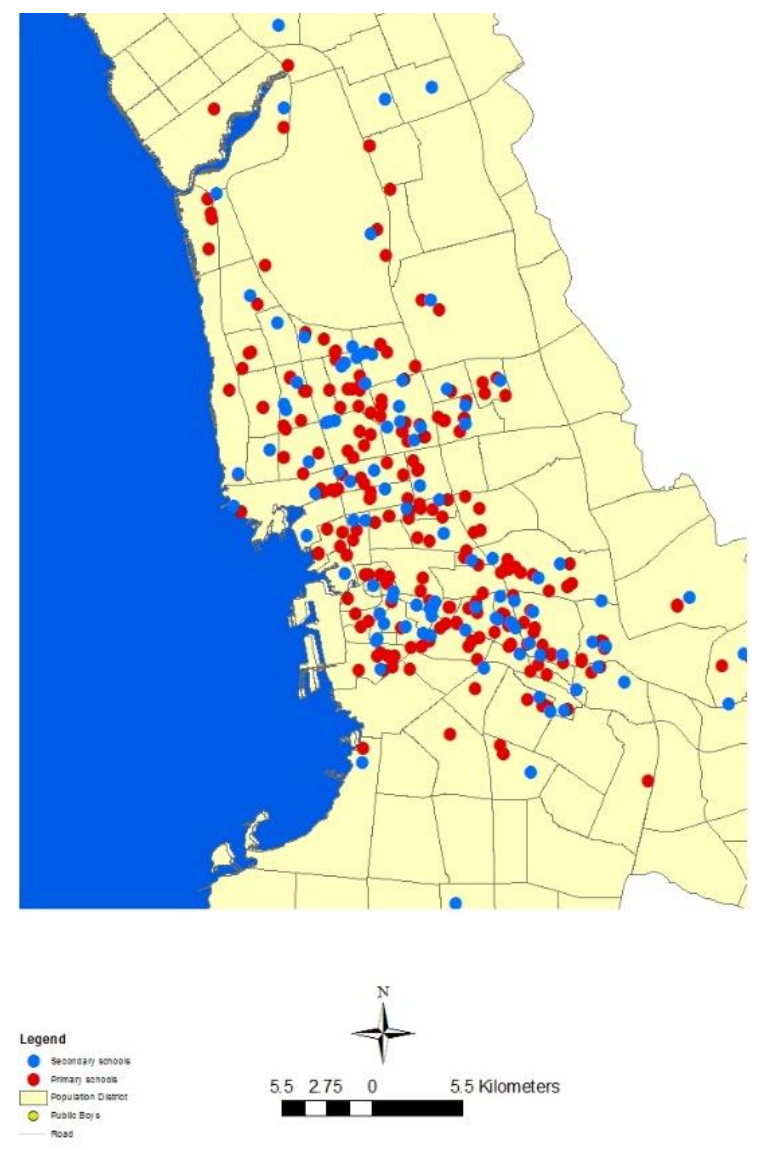

Fig. 1. Male Primary and Secondary Schools Location in Jeddah. 


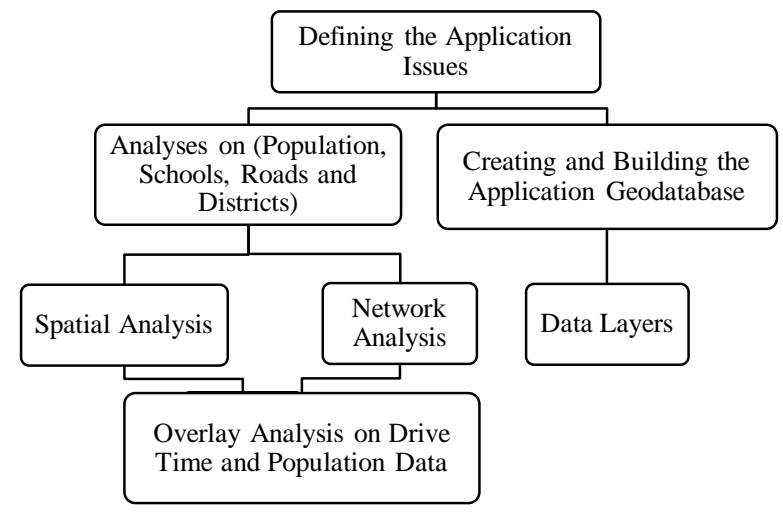

Fig. 2. Methodology Chart.

TABLE III. CHARACTERISATION OF DATA LAYER

\begin{tabular}{|l|l|l|l|}
\hline Layer Name & Layer Description & Feature Type & Attribute \\
\hline Land Use & $\begin{array}{l}\text { Districts/Neighborhood } \\
\text { Boundaries }\end{array}$ & Vector/Polygon & $\begin{array}{l}\text { NameArea, } \\
\text { Population }\end{array}$ \\
\hline Schools & School Types & Vector/Point & $\begin{array}{l}\text { Supply, } \\
\text { demand }\end{array}$ \\
\hline Roads & Road Networks & Vector/Line & Length, Time \\
\hline
\end{tabular}

\section{Spatial and Network Analysis}

Spatial analysis can solve multipart location-oriented problems and offer new perspectives to decision making. Overlay spatial analysis that includes schools' accessibility and population information, kernel density, and network analyses carried out using by this paper to provide an insight into the spatial access and distribution of schools in Jeddah. Firstly, Kernel density shows the quantity of the population for every point based on a quadratic formula with the maximum value at the point location and decreasing to zero at the search radius distance [16] (bandwidth) to obtain the density of features in the city districts.

Secondly, network analysis gives network-based spatial analysis tools for explaining complex routing issues via a configurable transportation network data model to represent unique network requirements [16] accurately. It calculates drive-times and locates facilities with poor accessibility. In many GIS software, the network analysis module comprises of a few modelling functions that include finding the shortest path, service area model and allocate model [26]. This paper utilised the Allocate and service area functions in ArcGIS Network Analyst for assessing schools' accessibility. Thus, it defines access to schools within the study area by estimating distances and solving other network problems using network connectivity. The distance along the definite travel direction is measured with the travel impedance between the source and destination and represented based on distance and time.

\section{RESULTS}

\section{A. Distribution of Schools in Jeddah}

Define This study classifies schools based on the number of students using the $500 \mathrm{~m}$ standard catchment area stated in Table I; in each school specifically to have an explicit nature of the distribution in each district. Fig. 3 and Fig. 4 GIS analyses clearly show the classification and variation in the number of students in primary and secondary schools, respectively. Both figures indicated an unequal distribution of students, with the central city districts having the highest number and it is justifiably because of the population concentration compared to the outer North and South of the city.

Furthermore, kernel density analysis carried out shows the concentration and relationship between the density of students existing in the study area. It describes the features (students) within each district of the city. A similar study carried out in 2018 on health care centres by Murad [26] stated that kernel density calculates the density of features in a neighbourhood around those features, it can calculate for both point and line features and he further presented, as shown below, the algorithm used to determine the default Kernel search radius (bandwidth) by Murad [26] is:

1) Calculate the mean centre of the input points. If a Population field other than None were selected, this, and the values would weight all the following calculations in that field.

2) Calculate the distance from the (weighted) mean centre for all points.

3) Calculate the (weighted) median of these distances, $D_{m}$.

4) Calculate the (weighted) Standard Distance, SD.

5) Apply the following formula to calculate the bandwidth:

Search Radius $=0.9 * \min \left(S D, \sqrt{1} \frac{1}{1 n(2)} * \mathrm{D} m\right) * n^{-0.2}$

where:

$\mathrm{SD}$ is the standard distance

$\mathrm{D}_{\mathrm{m}}$ is the median distance

$n$ is the number of points if no population field used, or if a population field supplies, $n$ is the sum of the population field value (number of students and classes).

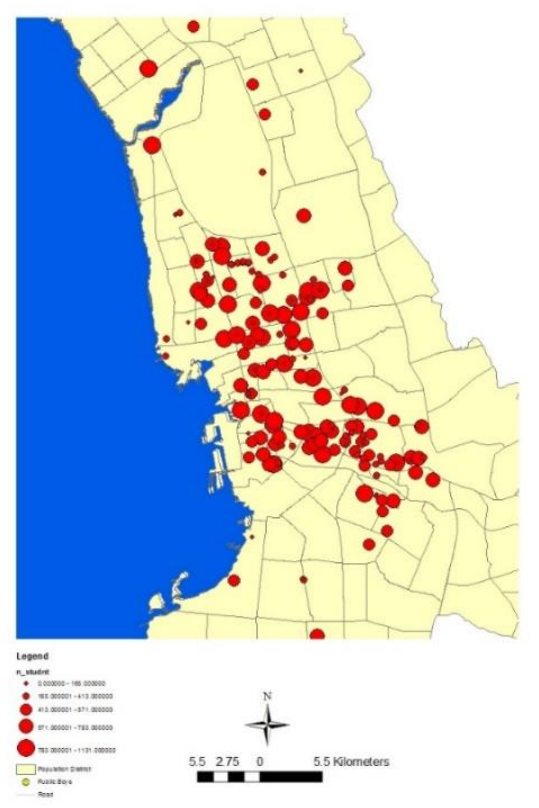

Fig. 3. Classification of Primary Schools based on the Number of Students. 


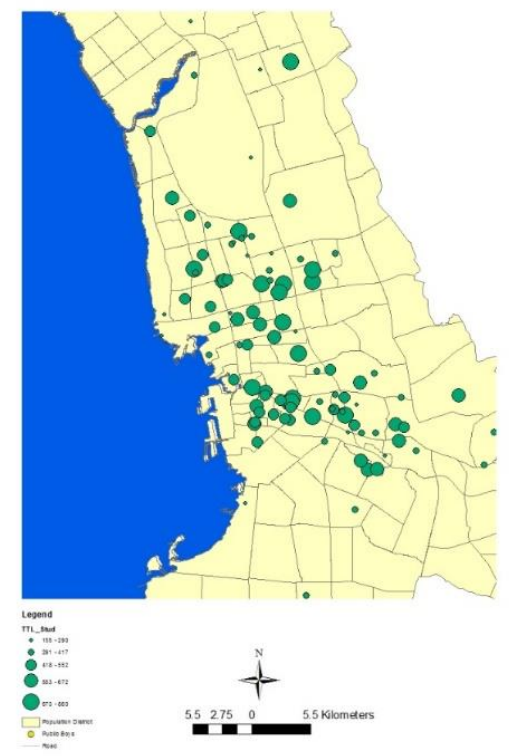

Fig. 4. Classification of Secondary Schools based on the Number of Students.

The presented algorithm calculated the schools' bandwidth based on the number of students in districts. Fig. 5 and Fig. 6 present the kernel density of both primary and secondary schools' students in the districts of Jeddah city and the darker the colour, the higher the density. Both analyses presented, indicated virtually similar results showing that concentration is more abundant in the central part of the city with a lower concentration in the less populated outer part (North, South, and East of Jeddah).

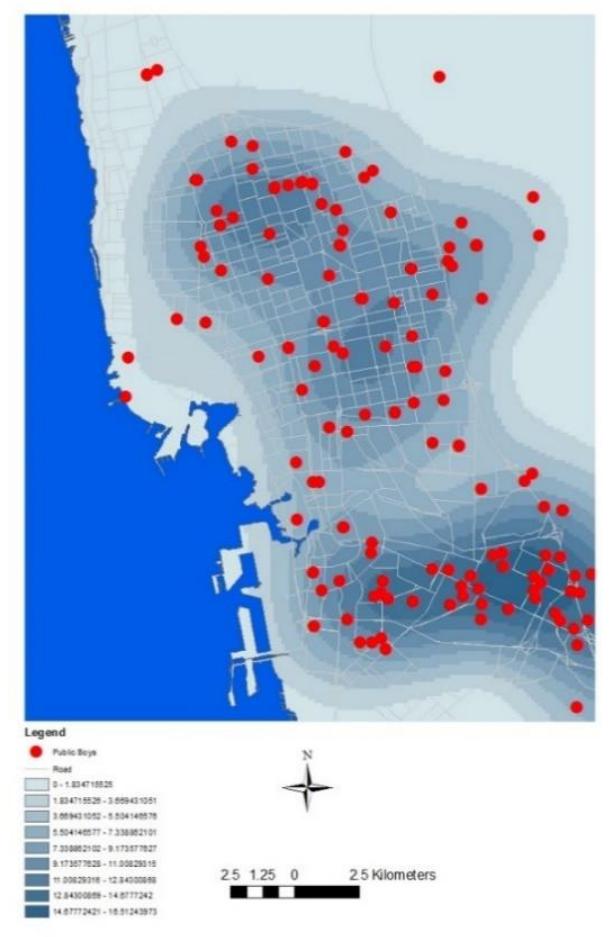

Fig. 5. Kernel Density of Students in Primary Schools.

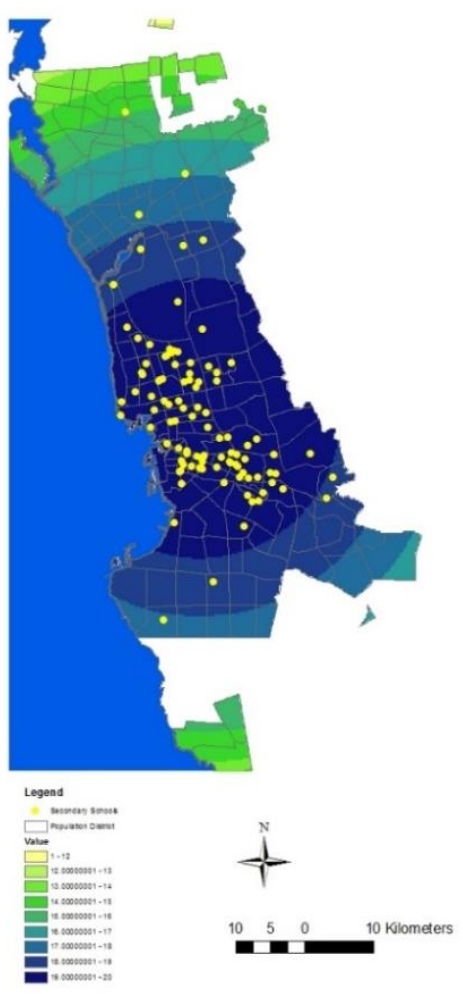

Fig. 6. Kernel Density of Students in Secondary Schools.

Additionally, GIS analysis can give a sense of direction by drawing highlights on a map, figuring the standard deviational ellipse and clarifies the directional growth of primary schools (Fig. 7) and secondary schools (Fig. 8) in Jeddah city. The tool analyse and clarifies the trend, utilising either the region of the feature or the region impacted by an attribute value related to the features. The latter is labeled as weighted standard deviation. Both analyses indicated that the directional growth is mainly in the concentrated city centre towards the western part where higher number of students are observed. The result could help authorities and planners have an objective understanding of the existing concentration and distribution of students and services in various districts of the city for better decision making and services improvement.

\section{B. Accessibility to Schools in Jeddah}

Accessibility to services, according to Murad [26] is a multidimensional concept that defines the connection between features of facilities and the features of the facility distribution framework. He further pointed out four main ways of measuring accessibility to health location, and the same way is applied for this paper but in this case, for public schools. So, network distance that calculates the length of the shortest route along the transportation network used considering its actual index accuracy, which produces accessibility regions, road network and travel time among the roads of the city. It gives the actual service areas when the connecting routes are clearly defined. Defining and estimating the adequate travel time to schools in Jeddah city, the 10-15 minutes (primary schools) and 30 minutes (secondary school) acceptable distance travel time standard to school given by the Saudi Arabia Ministry of Municipal and Rural Affairs is applied. Hence, this paper 
adopted 15 minutes' and 30 minutes' maximum drive time as the acceptable value for students to travel to primary and secondary schools respectively, taking into consideration the average speeds and speed restrictions on various street types and other physical hindrances to travel.

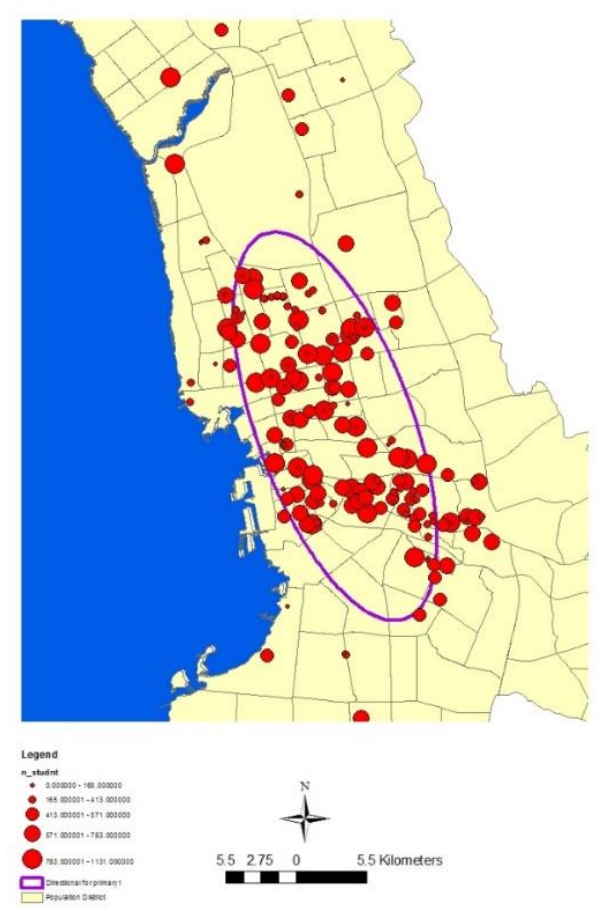

Fig. 7. Directional Growth of Primary Schools.

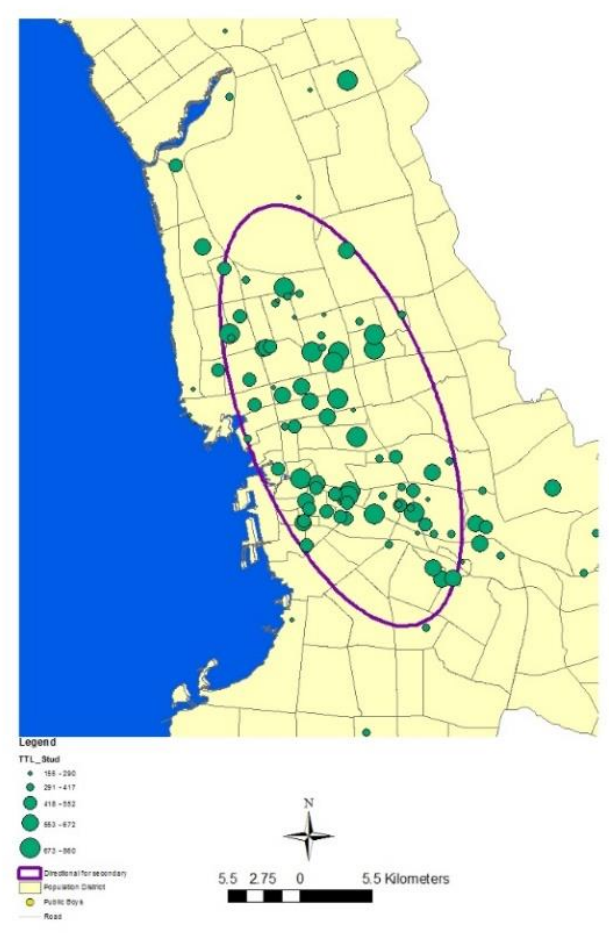

Fig. 8. Directional Growth of Secondary Schools.
Accessibility analysis carried out utilising the ArcGIS Network Analyst extension and created network service areas for existing male public schools' location in the study area. The resultant service zone is a zone which covers altogether the available path which is within $15 \mathrm{mins}$ and $30 \mathrm{mins}$ travel time to primary and secondary schools respectively. The resulting outcome of the drive-time service areas shown in Fig. 9 and 10 indicated the areas of the city that are well served and regions with low accessibility within the 15 minutes' (primary schools) and 30 minutes (secondary school) standard drive-time. Both the primary and secondary analyses show a similar pattern with the city centre, the north-western and northern part of Jeddah mostly covered. Therefore, most districts are well served $(60 \%$ of the city population), while the city parts that fall outside the standard drive time service area are within the outer part of the city where most are new districts with less population or parts industrial zones. From the results outcomes, it is apparent that the accessibility to schools in Jeddah city is to a more considerable extent commendable. However, the results give more insight into where the planners and authorities should focus on within the city.

\section{The Population within Access to Public Schools}

The population of students that falls within the access zones is obtained provided the service areas are well defined. Therefore, the drive-time analysis carried out in 3.2 presented a chance to define the served and unserved population. Fig. 9 and 10 presented correspondingly the results of the overlay analyses of the 15 minutes' and 30 minutes' drive-time of the population classification served and un-served population within access to the schools in districts of Jeddah (Fig. 13 and 14). The blue areas from both Fig. 11 and 12 indicated parts of the city with a high and served population. However, the red coloured areas in Fig. 13 and 14, respectively indicated the areas of the city with a high un-served population that require additional schools and these areas in the case of primary schools is higher if compared to secondary school that is very insignificant. Hence, the need for planners and authorities to consider increasing the number of schools around the red zones in the city centre to cover the un-served population.

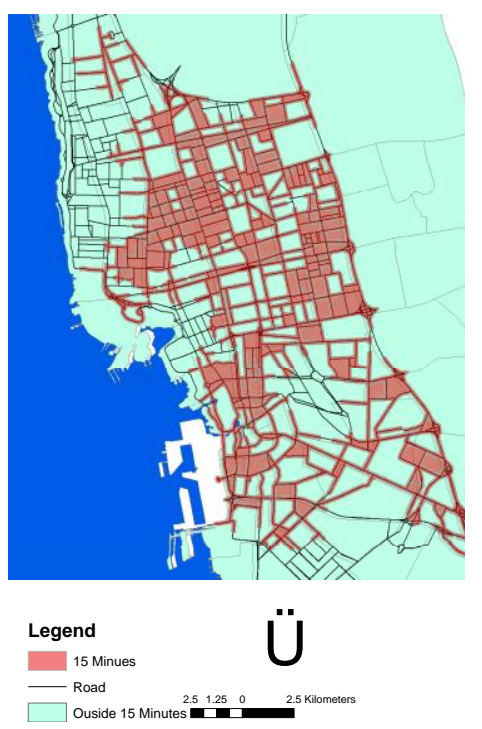

Fig. 9. 15 Minutes' Drive-Time Service Area for Primary Schools. 


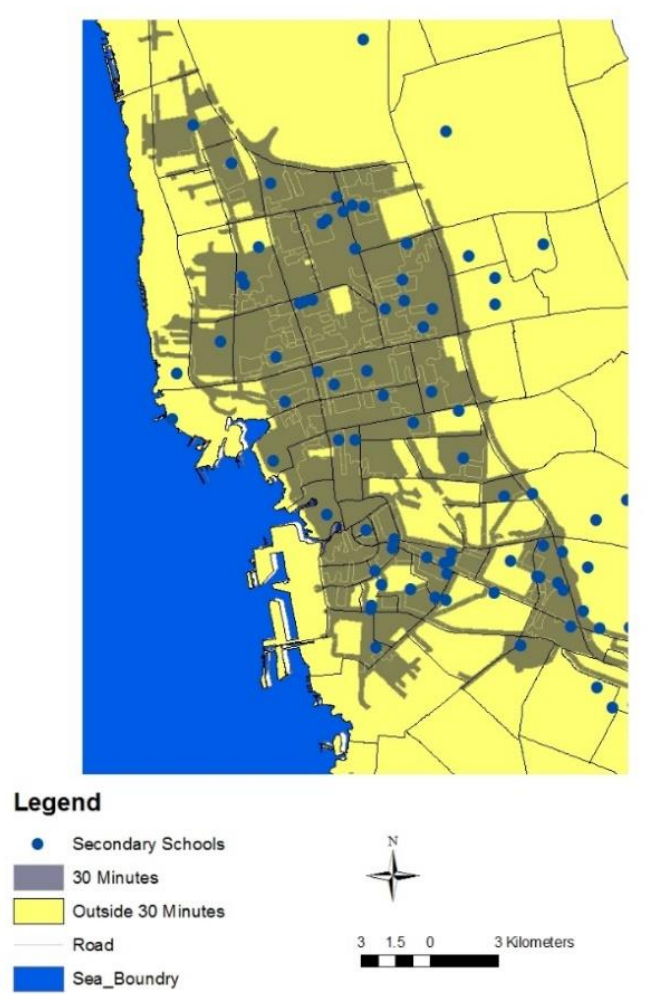

Fig. 10. 30 Minutes' Drive-Time Service Area for Secondary Schools.
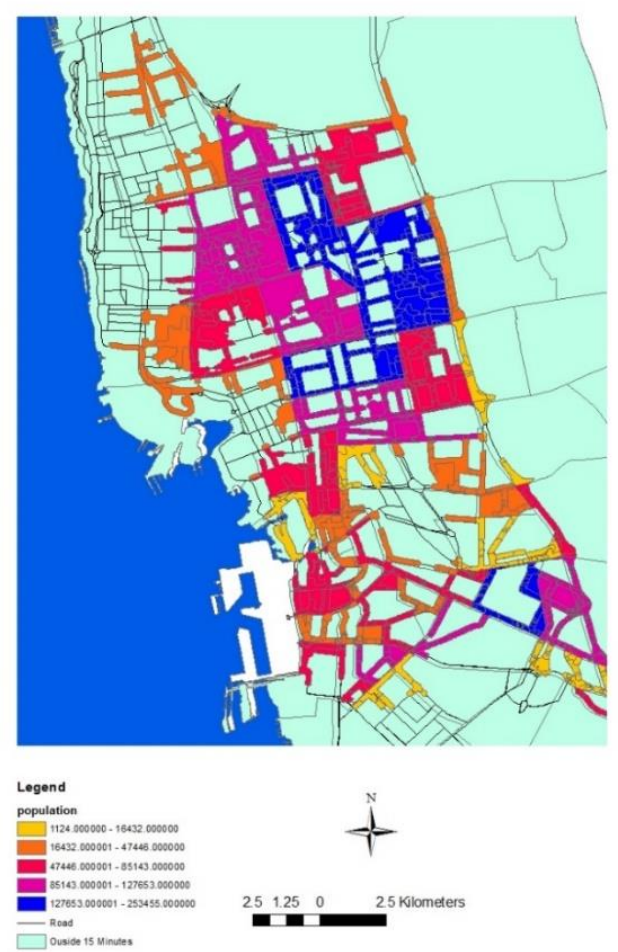

Fig. 11. Classification of the Population inside 15 Minutes' Drivetime Service Area for Primary Schools.

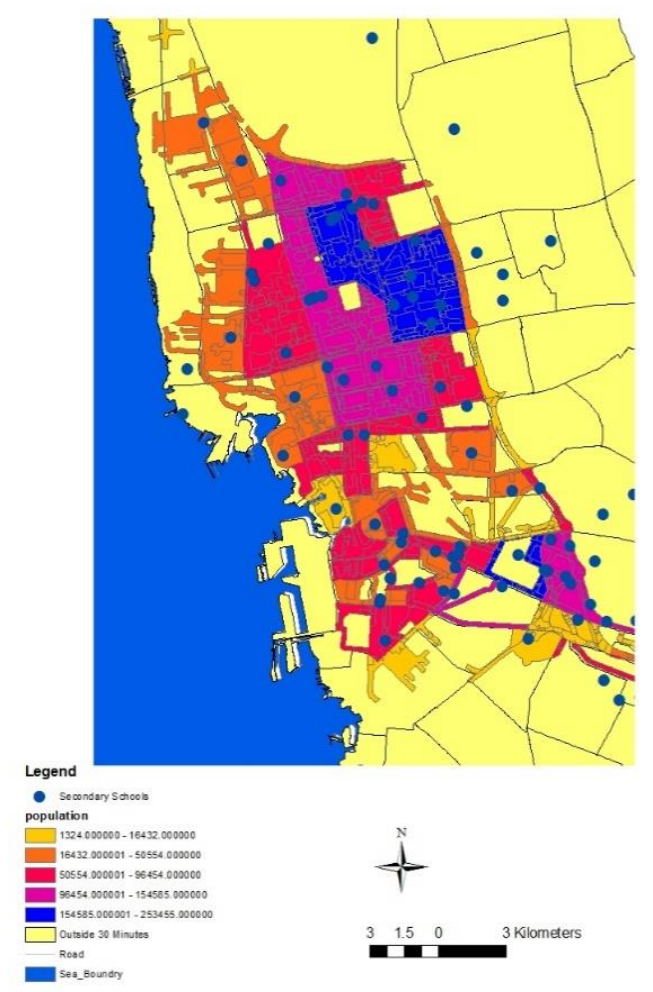

Fig. 12. Classification of the Population Inside 30 minutes' Drive Time Service area for Secondary Schools.

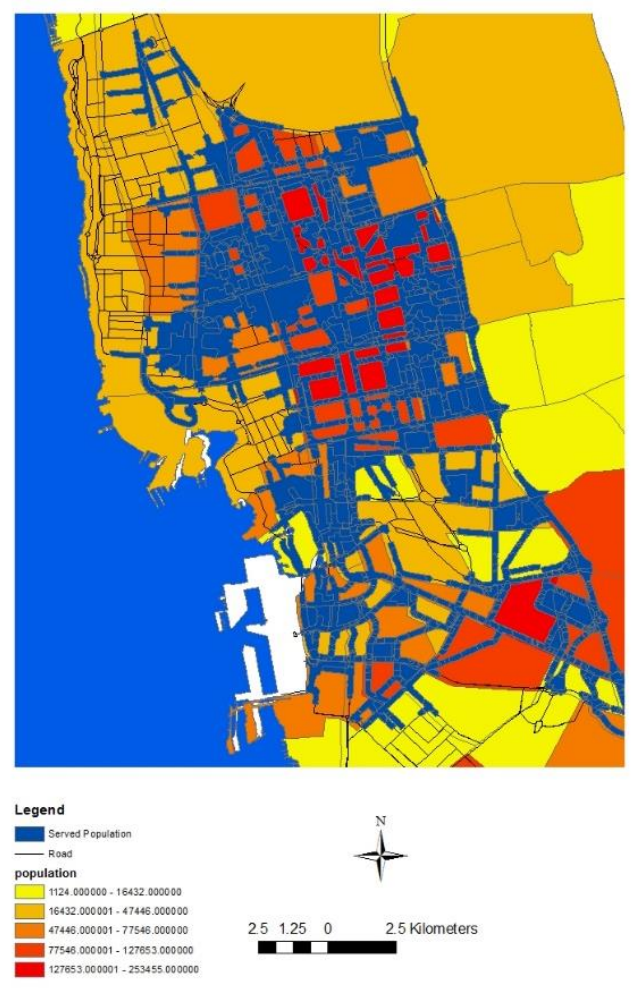

Fig. 13. Classification of Un-Served Population for Primary Schools. 


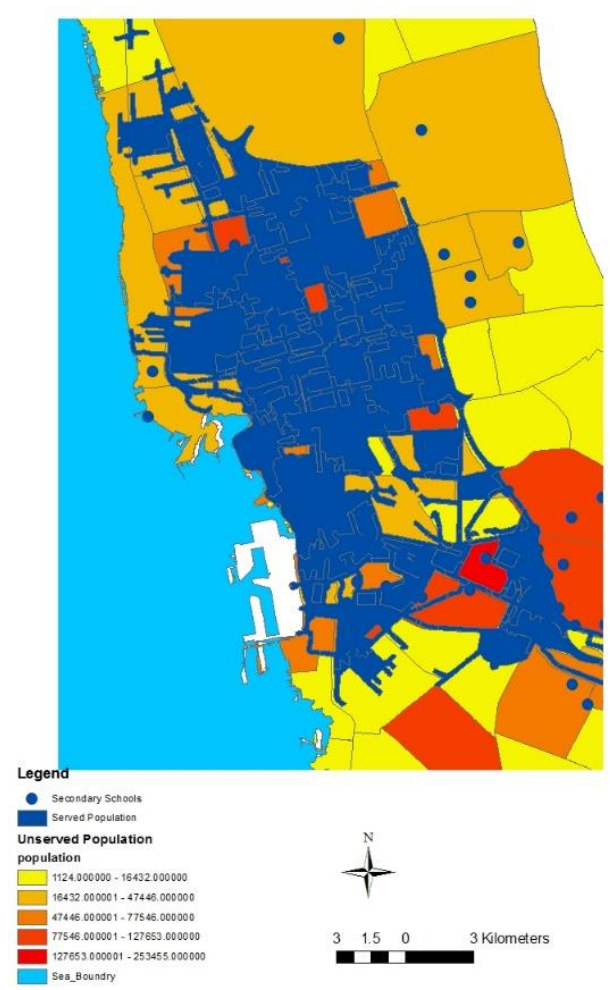

Fig. 14. Classification of Un-Served Population for Secondary Schools.

\section{Discussion}

The distribution of educational facilities needs to be a continuous process, and according to Department of Education report [2], functional and practical educational facilities could be planned and distributed based on a comprehensive plan of action to check possible shortages. For this study, there is an attempt to achieve spatial balance in the spreading of the male primary and secondary schools in the districts of Jeddah. While this appears to be achieved in some districts, the result of this study shows that GIS was not used to plan such facilities. However, the use of GIS technology identified the areas with shortages and access problems within the standard drive-time to schools. Meanwhile, the identification of the school locations (Fig. 1), the classifications of schools and students' population data (Fig. 3, 4, 5 and 6), show imbalances between the districts with high concentration and shorter travel distances in the central part of the city compared to the outer and less populated areas. A previous study carried out by Belarem et al. in 2018 mapped and analysed the school distribution and network in Makkah also shown a significant imbalance in the distribution of schools between the districts, lack of accelerated networks and public transport services to schools for ease of accessibility [9], therefore, it shows similar disparities with this study where the city centre has high schools' density compared to peripheral areas. Also, the results of a similar research carried out in Riyadh city [34], shows that the spatial distribution of schools in Oraija, Riyadh is adequate, however, the need to establish more schools to avoid overcrowding from the increasing number of students.
This study could be useful to authorities to address issues, for example, development of micro and macro plan of public schools particularly with the focus on access and dispersion by understudy's distribution by students. The research provided information for policymakers in Saudi Arabia to plan for both short and long term to build the effectiveness of schools' service management and for evaluating the performance of school services. Additionally, it is to note that studies in spatial distribution using GIS technologies have heaved in a brought thought. Unlike this paper that applied both spatial and network analysis for school distribution, most of the comparable studies utilised either spatial or network analysis to present their analyses, not both. For example, a previous study carried out in Jeddah city by Al-Enazi et al. used overlay and buffer analyses to only define the inequalities in school's distribution [12]. Moreover, two studies in Mukalla district in Yemen both used GIS technology also to assess the educational facilities distribution but the analyses did not go further to cover network analysis to assess the population within access to those education facilities $[3,35]$. Another similar and recent study carried out in Debre Markos Town in North-Western Ethiopia [19] unlike the presented cases only assess school spatial distribution and identify appropriate zones for the creation of new school sites according to schools' standards but not defining the service areas and drive-time that present a chance to define the served and unserved population.

So, this paper combined spatial and network analyses in analysing male public schools in Jeddah city to help in making meaningful choices, for example, selecting school's best locations and recognising best new schools' locations by authorities. Additionally, the paper found out that the old districts have more population within the standard drive if compared to the new and outer city districts that have low population and fewer services. Students in the old (central) districts have shorter travel distances to schools. This finding is supported by the works of Al-Enazi, Mesbah, and Anwar [12] who argued that the city centres are the areas with the most served population. Additionally, most of the previous studies on educational facilities just found out school distributions using GIS [4, 12, 18, 19, 20] and a study that applied drivetime to classify the served and un-served population in Saudi Arabia is not being reported until this study.

\section{CONCLUSION}

This paper explained that the use of GIS tools in understanding the distribution of educational facilities is one of the best methods as it gives a better understanding of spatial and network situations upon which schools' planning decisions are based. It provided information on the various spatial classification of schools carried-out about students' density and distance travel-time in the districts of Jeddah city. The result identified the imbalances in the planning of male public schools in Jeddah city to help Authorities address the current and future challenges, and most importantly to make the best improvements to raise the level of efficiency in the distribution. Also, the findings indicated the zones of the city with long travel distances. Thus, the utilisation of the GIS tools explains the relationship among various spatial issues by giving a more more apparent and impartial assessment upon which to base planning and implementation decisions, as well as to justify 
those decisions to policymakers. Finally, it is recommended that data update is required primarily for private and international schools by relevant authorities or subsequent researches so that more study is to be carried out for implementation, decision-making and services improvement in the education sector.

\section{REFERENCES}

[1] Altbach, P. G.; Gumport, P. J.; Berdahl, R.O. American higher education in the twenty-first century: Social, political, and economic challenges. JHU Press: Baltimore, USA, 2011.

[2] Department of Education. Educational Facilities Manual. Handbook on Educational Facilities: Integrating Disaster Risk Reduction in School Construction. Rev.ed. 2010.

[3] Lagrab, W.; Aknin, N. A Suitability Analysis of Elementary Schools Based Geographic Information System (GIS) A Case Study of Mukalla Districts in Yemen. Journal of Theoretical and Applied Information Technology 2017, Volume 95(4), pp. 731-742. Available Online: www.jatit.org/volumes/Vo195No4/2Vol95No4.pdf (accessed 5th November 2018).

[4] Ngigi, M. M.; Musiega, D.; Mulefu, F. O. Planning and Analysis of Educational Facilities using GIS: A Case Study of Busia County, Kenya. AGSE 2012. FOSS4G-SEA, pp. 261-269. Available Online: https://www.researchgate.net/publication/275209527_Planning_and_An alysis_of_Educational_Facilities_using_GIS_A_Case_Study_of_Busia_ County_Kenya (accessed 7th November 2018).

[5] Khobragade, S.; Kale, K. School Mapping System Using GIS for Aurangabad City. International Journal of Innovative Research in Computer and Communication Engineering 2016. Volume 4. 1711017119. DOI: 10.15680/IJIRCCE.2016.0410002.

[6] Ekpoh, U. I. School Mapping and Facility Planning. Educational Planning in Nigeria: Principles and Practices. University of Calabar Press: Calabar, Nigeria, 2018. Available Online: https://www.researchgate.net/publication/332804564_School_mapping_ and_facility_planning (Accessed on 1st December 2019).

[7] Akpakwu, S. O. Principles and techniques of education. Makurdi: Destiny ventures: Makurdi, Benue, Nigeria, 2012.

[8] Adaja, C. F.; Osagie, R. O. Politics of school mapping and facility provision in higher education in Nigeria. In Politics of education and national development in Nigeria, N. M. Abraham, Durosaro, D. O et. al. University of Port Harcourt Press: Port Harcourt, Nigeria, 2015, pp. 8186.

[9] Belarem, M., Hamza, M., Jamil, A.; Ajmi, M. Mapping and Analysis of the School Network of Makkah Al-Mukarramah (Saudi Arabia), Jeddah Girls' Secondary Schools as Example. Current Urban Studies, 2018, Volume 6, pp. 102-120. DOI: 10.4236/cus.2018.61005.

[10] General Authority for Statistics. 2019. Available online: http://www.data.gov.sa/en/general-authority-statistics (accessed on $9^{\text {th }}$ November 2019).

[11] Ministry of Education. 2018. Available online: http://www.data.gov. sa/en/ministry-education-0 (accessed on $9^{\text {th }}$ November 2018).

[12] Al-Enazi, M.; Mesbah, S.; Anwar, A. Schools Distribution Planning using GIS in Jeddah City. International Journal of Computer Applications 2016, Volume 138 (1), pp. 33-36. http://www.ijcaonline .org/research/volume138/number1/alenazi-2016-ijca-908693.pdf

[13] Steinberg, S. L.; Steinberg, S.J. GIS Research Method: Incorporating Spatial Perspectives. Esri Press: Redlands, California, 2015.

[14] Xia, L. and Yeh, A. G. Modelling sustainable urban development by the integration of constrained cellular automata and GIS, International Journal of Geographical Information Science 2000, Volume 14(2), 131152, DOI: $10.1080 / 136588100240886$

[15] Graham, S. R.; Carlton, C.; Gaede, D.; Jamison, B. The benefits of using geographic information systems as a community assessment tool. Public health reports 2011, Volume 126(2), pp. 298-303.
[16] ESRI. 2018. Available online: https://www.esri.com/en-us/arcgis/aboutarcgis/overview (accessed on $19^{\text {th }}$ December 2018).

[17] Musa, H. D. \& Mohammed, B. B. An Analysis of Spatial Distribution of Primary and Secondary Schools in Bida Town, Nigeria. Abuja Journal of Geography and Development 2011. Volume 3 (2), pp. 31-33.

[18] Al-Rasheed, K.; El-Gamily H. GIS as an Efficient Tool to Manage Educational Services and Infrastructure in Kuwait. Journal of Geographical Information Systems 2013.

[19] Aschale, T. M. Assessment of Schools Spatial Distribution and Identifying Suitable Areas by Using GIS Technology: In Case of Debre. Journal of Resources Development and Management 2017, Volume 35, pp. 8.

[20] Olubadewo, O. O., Abdulkarim, I. A., \& Ahmed M. The Use of GIS as Educational Decision Support System (EDSS) for Primary Schools in Fagge Local government Area of Kano State, Nigeria. Academic Research International 2013, Volume 4(6), pp. 614-624.

[21] Canfield, J. P., Joseph, N., Dana H., Ashley H., and Willie E. Using a Person-Centered Approach to Examine the Impact of Homelessness on School Absences. Child and Adolescent Social Work Journal 2016, Volume 33 (3), pp. 199-205.

[22] Urban Institute. The Road to School How Far Students Travel to School in the Choice-Rich Cities of Denver, Detroit, New Orleans, New York City, and Washington, DC, 2018. Available online: https://www. urban.org/sites/default/files/publication/97151/the_road_to_school_7.pd $f$ (accessed on $25^{\text {th }}$ June 2019).

[23] Saudi National e-Government Portal. 2018. Available online: http://www.data.gov.sa/en/ministry-municipal-and-rural-affairs (accessed on $10^{\text {th }}$ November 2018).

[24] Wang, J. J.; Jing, Y. Y.; Zhang, C. F.; Zhao, J. H. Review on MultiCriteria Decision Analysis Aid in Sustainable Energy Decision-Making. Renew Sustain Energy Rev. 2009; 13:2263-78.

[25] Sayed-Ahmed, M.; Shehata, E.; Sennah, K. Development of Creep Model for Structural Insulated Timber-Foam Sandwich Walls Under Sustained Soil Pressure in Basements of Residential Buildings. Proc AlAzhar University English Conference, 2010, Volume 5. pp. 603-614.

[26] Murad, A. Using GIS for Determining Variations in Health Access in Jeddah City, Saudi Arabia. International Journal of Geo-Information 2018, volume 7, pp. 245.

[27] UNESCO. 2019. Saudi Arabia: Education and Literacy. Available online: http://uis.unesco.org/country/SA (accessed on $9^{\text {th }}$ May 2019).

[28] Al-Sadaawi. A. Saudi national assessment of educational progress, International Journal of Educational Policy and Leadership 2010, Volume 5, pp. 1-14. http://journals.sfu.ca/ijepl/index.php/ijepl/article/ view/202/100

[29] Al-Sadan, I. A. Educational assessment in Saudi Arabian schools. Assessment in Education: Principles, Policy \& Practice 2000, Volume 7(1), pp. 143-155.

[30] Algarni, F. and Male, T. Leadership in Saudi Arabian Public Schools: Time for Devolution? ISEA 2014, Volume 42(3), pp. 45-59.

[31] Alyami, R. H. Educational Reform in the Kingdom of Saudi Arabia: Tatweer Schools as a Unit of Development. Literacy Information and Computer Education Journal (LICEJ) 2014, volume 5(2), pp. 15151524.

[32] Saudi Arabian Cultural Mission. Educational System in Saudi Arabia. SACM: Washington D.C, USA, 2006.

[33] Prokop, M. Saudi Arabia: The politics of education. International Affairs 2003, Volume 79, pp. 77-89

[34] Al Zeer, N. M. (2005). ANALYSIS of the Spatial Distribution of Public Secondary Girls' and Boys' Schools in Riyadh, Saudi Arabia. (Doctoral dissertation, University of Leicester).

[35] Lagrab, W. and N. Aknin, N. Analysis of Educational Services Distribution-Based Geographic Information System (GIS). International Journal of Scientific \& Technology Research 2015, volume 3. pp. 113118. 